\title{
OPTIMASI ALTERNATIF METERAN AIR BERBASIS IOT
}

\author{
Merpati V. A. Nalle, Sentot Achmadi, Ali Mahmudi \\ Program Studi Teknik Informatika S1, Fakultas Teknologi Industri \\ Institut Teknologi Nasional Malang, Jalan Raya Karanglo km 2 Malang, Indonesia \\ Merpatinalle02@gmail.com
}

\begin{abstract}
ABSTRAK
Permasalahan yang timbul dimasyarakat terkhususnya masayarakat NTT kupang pada saat musim kemarau adalah penyediaan air bersih dari PDAM yang mengalami penurunan bahkan mengalami macet (air tidak mengalir). Akan tetapi angka pada perhitungan meteran air tetap bertambah, dan setiap bulannya tetap dicatat oleh petugas PDAM. Kemudian meteran air yang digunakan PDAM juga masih manual, dimana pencatatan penggunaan air dilakukan oleh petugas PDAM dengan mendatangi setiap rumah pelanggan. Sistem optimasi alternatif meteran air berbasi IOT dapat menjadi solusi dari permasalahan yang diuraikan. sistem dilengkapi dengan pendeteksian air, dan memanfaatkan Aplikasi Telegram sebagai pemberitahuan pada pelanggan ada atau tidaknya air yang terdeteksi. Sistem juga dilengkapi pencatatan penggunan air secara otomatis, sehingga petugas PDAM tidak perlu datang kerumah masyarakat untuk mencatat penggunaan air. Hasil yang dicapai dari penelitian ini pelanggan dapat mengetahui secara pasti, bahwa ada air yang dialirkan atau tidak melalui aplikasi Telegram, pada pengujian sensor water flow untuk menghitung volume debit air didapati presentase error sebesar $0.1207 \%$. Dan pengujian Solenoid valve masih menunjukan selisih dimana selisih terbesar saat selonoid valve membuka katup adalah 02.40.00 menit, dan saat menutup katup sebesar 01.02.00 menit.
\end{abstract}

Kata Kunci : PDAM, optimasi, Meteran air, Telegram, IOT

\section{PENDAHULUAN}

Air merupakan ciptaan TUHAN yang sangat penting bagi kehidupan makhluk hidup di bumi, salah satunya adalah manusia. Air sangat berguna untuk memenuhi kebutuhan manusia sehari-hari seperti minum, masak, mandi dan lainnya. Dalam usaha menyediakan air bersih bagi masyarakat salah satu BUMD di Indonesia yaitu PDAM (perusahaan daerah Air Minum) bertugas dalam mengelola dan mensuplai air untuk masyarakat.

Dalam penyaluran air bersih ada beberapa permasalahan yang dialami masyarakat NTT terkhususnya di daerah kupang dimana pada saat musim kemarau mengalami penurunan debit aliran air, yang mengakibatkan penyaluran air untuk setiap masyarakat menggalami kendala bahkan macet (air tidak mengalir). Akan tetapi angka pada perhitungan meteran air tetap bertambah, dan setiap bulannya tetap dicatat oleh petugas PDAM. Kemudian meteran air yang digunakan oleh PDAM masih manual dan belum dilengkapi sistem pencatatan pemakain air otomatis.

Dari sistem lama yang digunakan pihak PDAM untuk mencatat penggunaan air pelanggan, petugas akan mendatangi setiap rumah pelanggan untuk mencatat langsung angka pada meteran analog. Pencatatan pemakaian air yang dilakukan petugas juga dijadwalakan setiap bulan atau setiap pertanggal dalam satu bulan untuk melakukan pencatatan penggunaan air.

Dari uraian yang disampaikan maka dibuatlah sistem optimasi alternatif meteran air berbasis IOT yang dilengkapi dengan pendeteksian air, dan memanfaatkan Aplikasi Telegram sebagai pemberitahuan pada pelanggan ada atau tidaknya air yang terdeteksi. sistem dilengkapi dengan katup solenoid valve, dimana katup solenoid valve akan terbuka sebagai jalannya air ketika sistem mendeteksi adanya air, dan akan tertutup jika tidak terdeteksi adanya air, agar mencegah jalannya udara untuk menggerakan sensor water flow.

Dari sistem yang dibuat, juga dilengkapi pencatatan penggunan air secara otomatis, sehingga petugas PDAM tidak perlu datang kerumah masyarakat untuk mencatat penggunaan air. Agar dapat membantu pihak petugas dan pihak pelanggan dalam memonitoring penggunaan air.

\section{TINJAUAN PUSTAKA}

\subsection{Penelitian Terdahulu}

Penelitian mengenai pendeteksian air telah dilakukan oleh Wahyu Indianto, Awang Harsa Kridalaksana, Yulianto (2017). Dalam penelitiannya, Wahyu dkk melakukan pendeteksi banjir peringatan dini menggunakan sensor air dan sensor ultrasonic untuk mengukur ketinggian air. Status ketinggian air akan dikirim oleh sistem PHP dan sms gateway(Gammu). (Wahyu Indianto, Awang Harsa Kridalaksana, Yulianto, 2017) [1].

Kemudian di tahun yang sama Puthut Kurniawan (2017), mengembangkan sistem pendeteksian kebocoran serta pengurasan air secara otomatis pada kapal. Pada sistem tersebut sensor water level digunakan sebagai deteksi air dan submersible pump sebagai alat penguras air. Apabila ada air yang masuk kedalam blok kapal yang dideteksi oleh sensor water level maka pompa akan 
bekerja untuk menguras air. (Puthut Kurniawan, 2017)[2].

Penelitian mengenai monitoring air telah dilakukan oleh Sutono (2016), dalam penelitian tersebut Sutono membuat sistem yang dapat mengontrol volume air yang mengalir pada tiap-tiap kran pelanggan, dengan melakukan pemberian waktu terbuka masing-masing keran. Perhitungan volume air dilakukan dengan menambahkan debit air tiap detik yang melewati sensor waterflow[3].

Pada tahun 2017 I Made Nova Suardiana dkk, melakukan pengembangan sistem monitoring air. Dalam penelitian yang dilakukan I Made Nova Suardiana dkk, menggunakan sensor waterflow Arduino untuk mengganti flow meter analog untuk pengukuran jumlah penggunaan debit air. I Made Nova Suardiana dkk menggunakan sms dan LCD untuk menampilkan informasi jumlah pemakain secara real time [4].

\subsection{Sistem monitoring}

Sistem monitoring atau sistem pengawasan adalah suatu upaya yang sistematik untuk menetapkan kinerja standar pada perencanaan untuk merancang sistem umpan balik informasi, untuk membandingkan kinerja aktual dengan standar yang telah ditentukan, untuk menetapkan apakah telah terjadi suatu penyimpangan tersebut, serta untuk mengambil tindakan perbaikan yang diperlukan untuk menjamin bahwa semua sumber daya perusahaan atau organisasi telah digunakan seefektif dan seefisien mungkin guna mencapai tujuan perusahaan atau organisasi[5].

\subsection{Sensor waterflow YF-S201}

Sensor water flow atau flow meter adalah alat yang digunakan unutuk mengukur laju aliran air dari suatu fluida yang mengalir dalam pipa atau sambungan terbuka. Waterflow terdiri dari bodi badan kuningan, rotor air dan sensor hall effect. Prinsip kerja dari alat ini adalah ketika aliran air melewati rotor air, magnetic rotor berputar. Dan hall effect akan mengirimkan pulse signal ke pengontrol.

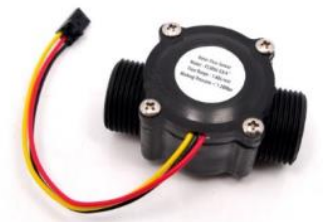

Gambar 1. Sensor waterflow

Water flow sensor YF-S201 memiliki diameter input aliran air $1 / 2$ inch atau sama dengan $1,25 \mathrm{~cm}$, memiliki panjang $5,6 \mathrm{~cm}$. Terdapat 3 kabel penghubung untuk mengoperasikan sensor ini yaitu:

1.Kabel berwarna merah : hubungan ke Vcc

2.Kabel berwarna kuning : hubungan ke Data

3. Kabel berwarna hitam : hubungan ke Ground

$$
(Q)=\frac{\text { pulse Frequency } / 60}{7.5}
$$

Persamaan (1) merupakan persamaan untuk mendapatkan nilai aliran air dalam satuan L/detik. Q merupakan nilai aliran air dalam satuan L/detik. Angka 7.5 adalah konstanta untuk water flow sensor YF-S201 dalam keadaan horizontal. Angka 60 adalah faktor pengali waktu untuk satuan L/detik.[4]

\subsection{Solenoid Valve}

Solenoid valve adalah katup yang digerakkan oleh energi listrik, mempunyai kumparan sebagai penggeraknya yang berfungsi untuk menggerakan piston yang dapat digerakan oleh arus AC maupun DC. Solenodi valve bekerja berdasarkan input tegangan dan arus, yang mana saat solenoid ini bekerja tegangan yang diterima pada solenoid-nya kurang lebih 24 volt dengan syarat tidak ada pembebanan dan arus yang diterima kurang lebih 0,2 ampere. [6]

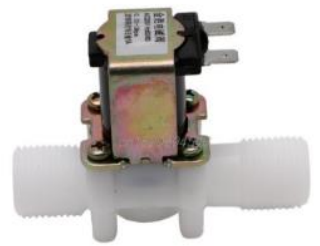

Gambar 2. Solenoid Valve

\subsection{Sensor water level}

Sensor water level ini dirancang untuk mendeteksi keberadaan dan ketinggan air, Terdiri dari tiga bagian: sebuah electronic brick connector, resistor 1 MQ. Sensor water level memiliki 10 rangkaian seri tembaga, dengan 5 diantaranya adalah jalur power, dan 5 lainnya adalah jalur pendeteksi.

Water level sensor ini dapat menentukan ukuran ketinggian air dengan merubah menjadi sinyal analog, dan nilai nilai analog dari output dapat digunakan secara langsung dalam mode program. [7]

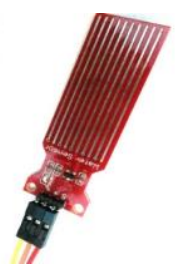

Gambar 3. Sensor water level

\subsection{Nodemcu ESP8266}

NodeMCU dapat diartikan sebagai board arduino yang dilengkapi dengan ESP8622. ESP8266 dalam NodeMCU sudah terintergrasi dengan berbagai fitur selayaknya microkontroler dan ditambah dengan kapalitas akses terhadap wifi dan juga chip komunikasi yang berupa USB to serial. Sehingga hanya diperlukan kabel USB untuk memprogramnya $[8]$ 


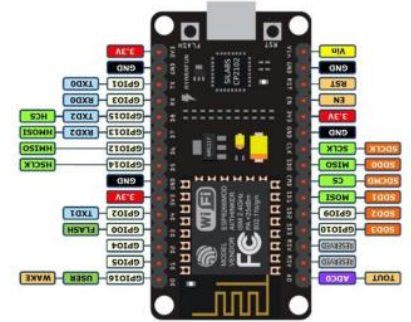

Gambar 4. Nodemcu ESP8266

\subsection{Arduino Uno}

Arduino Uno adalah papan sirkut mikrokontroler berbasis ATmega328. IC (integrated circuit) ini memiliki 14 digital pin input/output, dengan 6 pin sebagai output PWM, 6 pin input analog, $16 \mathrm{MHz}$ resonator keramik, koneksi USB, jack catu daya eksternal, header ICSP, dan tombol reset. Ini semua berisi hal-hal yang diperlukan untuk mendukung mikrokontroler; sederhana saja, hanya dengan menghubungkannya ke komputer dengan kabel USB atau sumber tegangan dengan adaptor AC-DC dan atau baterai untuk memulai menggunakan papan Arduino. [9]

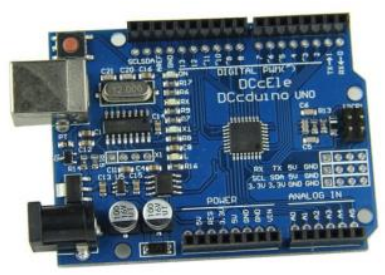

Gambar 5. Arduino Uno

\subsection{Aplikasi telegram Bot}

Telegram bot adalah sebuah bot atau robot yang diprogram dengan berbagai perintah untuk menjalankan serangkaian instruksi yang diberikan oleh pengguna. Bot ini hanyalah sebuah akun Telegram yang dioperasikan oleh perangkat lunak yang memiliki fitur $A I$.

Bot Telegram dapat melakukan apa saja sesuai perintah (yang sudah tersedia). Bot telegram bisa digunakan untuk melakukan pencarian, sebagai penghubung, pengingat, pengajar, pengintegrasi, dan lainnya. [10]

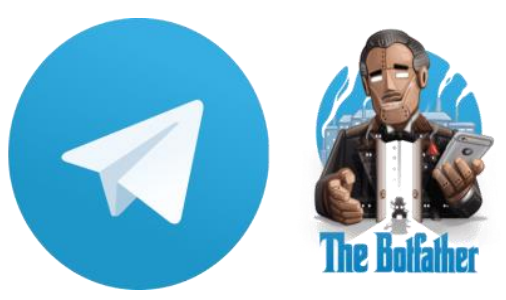

Gambar 6.Telegram Bot

\section{METODE PENELITIAN}

\subsection{Flowchart sistem}

Pada Flowchart sistem dijelaskan proses berjalannya aplikasi seperti yang ditunjukkan pada Gambar 7.

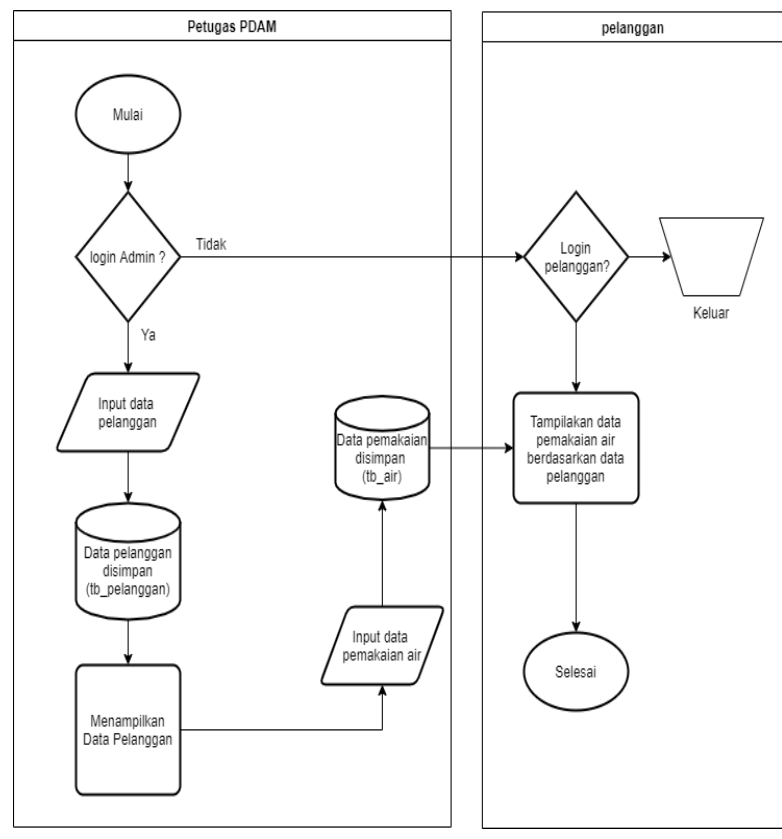

Gambar 7. Flowchart sistem

Pada awal sistem akan melakukan login, jika login sebagai admin maka sistem akan menampilkan dashbor admin, untuk melakukan input data pelanggan, setelah melakukan penginputan maka data disimpan pada tb_pelanggan dan menampilkan data tersebut pada dashbor admin. Jika login sebagai pelanggan maka sistem akan menunjukan halaman home untuk monitoring jumlah pemakaian air dan harga pemakaiannya

\section{2. flowchart sistem Telegram Bot}

Flowchart sistem ini menjelaskan proses berjalananya pengecekan air dari Telegram seperti ditunjukkan pada Gambar 8.

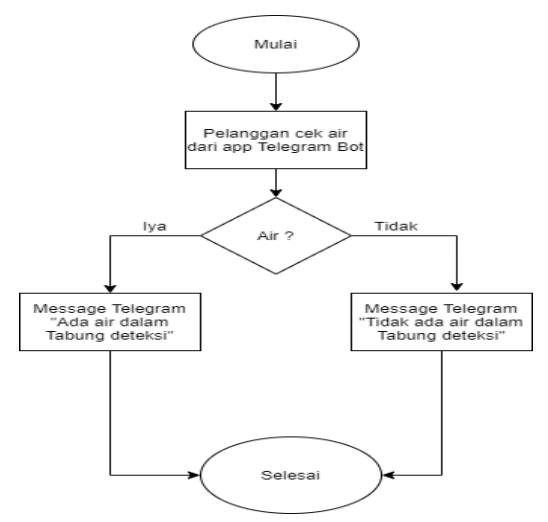

Gambar 8. Flowchart sistem Telegram bot 
Pada awal sistem, pelanggan akan mengakses telegram dari smartphone atau laptob, kemudian mengakses bot chat "water". Setelah mengakses bot "water", pelanggan dapat mengecek keberadaan air pada alat dengan mengirimkan chat "cek air" pada bot, setelah pesan dikirim maka pelanggan akan mendapatkan balasan dari bot. jika pada alat terdeteksi air maka bot akan mengirimkan chat balasan "ada air di tabung deteksi" sedangkan jika tidak terdeteksi air maka bot akan mengirim "Tidak ada air dalam tabung deteksi”.

\subsection{Flowchart alat}

Pada Flowchart alat dijelaskan proses cara kerja alat. Seperti yang ditunjukkan pada Gambar 9:

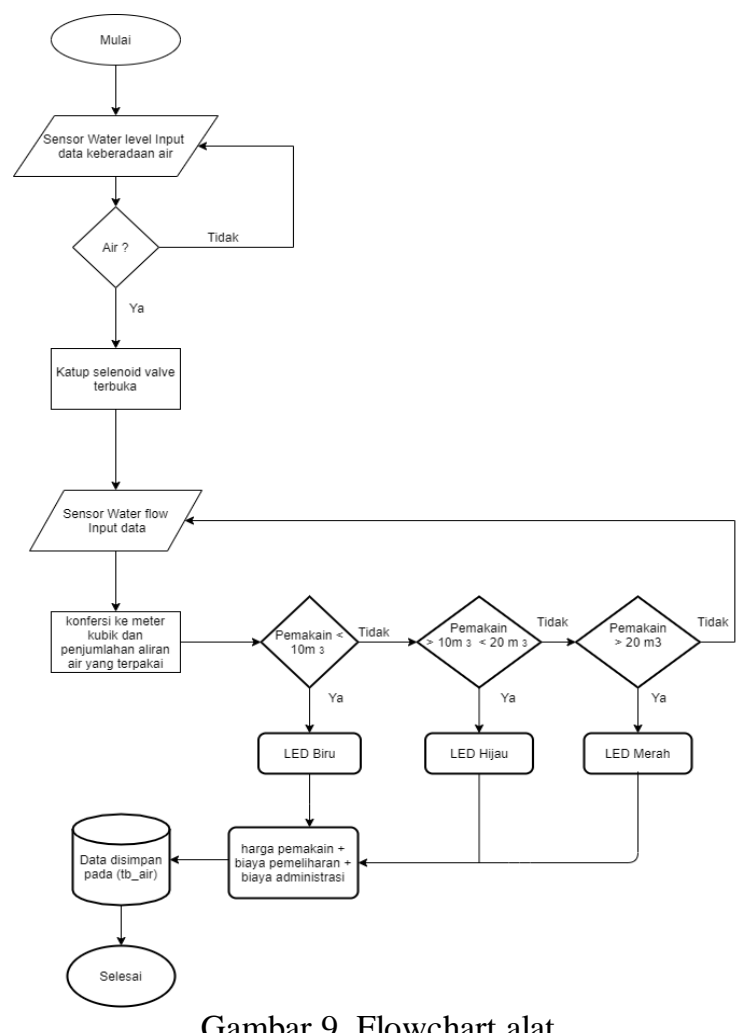

Pertama sensor water level akan mendeteksi ada dan tidaknya aliran air. Kemudian setelah sensor water level mendeteksi adanya air, katup solenoid valve akan terbuka untuk jalannya aliran air melewati sensor water flow, jika tidak terdeteksi adanya air maka katup solenoid valve akan tetap tertutup, untuk mencegah tekanan udara yang ada didalam pipa menggerakan water flow sensor.

Setelah aliran air melewati sensor water flow, maka sensor water flow akan melakukan perhitungan penggunaan aliran air. Kemudian data akan disimpan pada webserver. Jika pemakaian air kurang dari $10 \mathrm{~m}^{3}$ maka LED biru akan nyala, jika pemakaian lebih dari $10 \mathrm{~m}^{3}$ dan kurang dari $20 \mathrm{~m}^{3}$ maka LED, sedangkan jika pemakaian lebih dari $20 \mathrm{~m}^{3}$ maka LED merah akan menyala.

\subsection{Use case diagram}

Use Case diagram adalah urutan interaksi antara sistem dan actor yang saling berkaitan. Pada sistem optimasi alternatif meteran air berbasis IOT memiliki 2 aktor yaitu Admin PDAM dan pelanggan yang di tunjukan pada gambar 10.

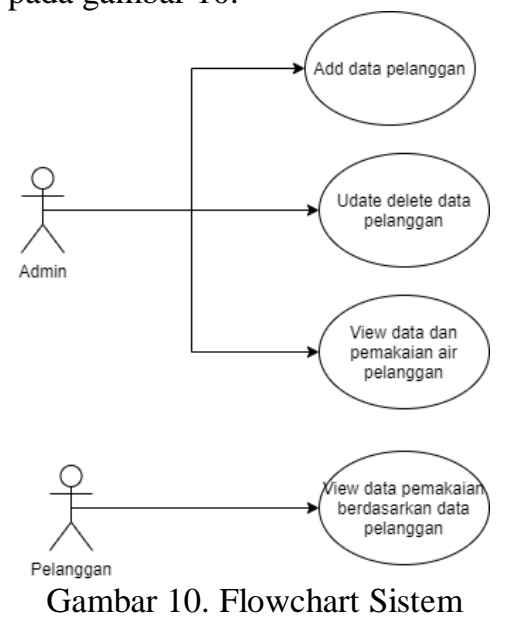

Pada gambar 10 aktor Admin mempunyai hak akses untuk melakukan operasi CRUD pada data pelanggan dan menampilkan data pelanggan. sedangkan untuk pelanggan hanya dapat melihat/view data pelanggan dan data pemakaian jumlah air.

\section{HASIL DAN PEMBAHASAN}

\subsection{Pengujian Website Pelanggan dan admin}

Pengujian website terdiri dari 2 bagian yaitu sisi pelanggan dan sisi admin. Pada sisi pelanggan dilakukan pengujian menampilkan data pelanggan serta monitoring jumlah pemakaian air berdasarkan pelanggan yang sedang Login. Sedangkan pada sisi Admin dilakukan pengujian perhitungan biaya pemakaian berdasarkan golongan pelanggan.

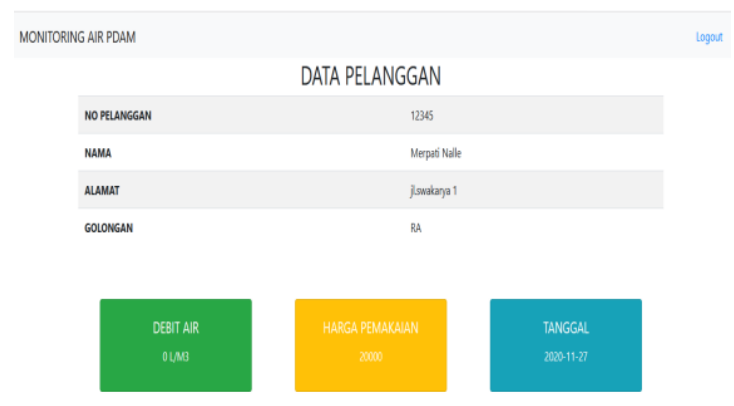

Gambar 11. Pengujian Website Pelanggan

Pada pengujian website sisi pelanggan, dapat menampilkan data pelanggan serta pemakaian air berdasarkan pelanggan yang Login. 


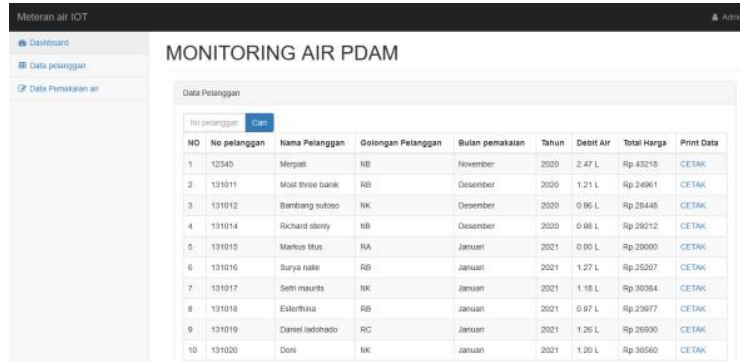

Gambar 12. Pengujian website admin

Pada pengujian website sisi admin, dapat melakukan perhitungan harga total penggunaan air berdasarkan golongan pelanggan.

Tabel1. perhitungan Golongan PDAM Kab.Kupang

\begin{tabular}{|l|l|l|}
\hline NO & $\begin{array}{l}\text { GOLONGAN } \\
\text { PELANGGAN }\end{array}$ & HARGA/ltr \\
\hline 1 & Rumah tangga A (RA) & Rp.3.700 \\
\hline 2 & Rumah tangga B (RB) & Rp.4.100 \\
\hline 3 & Rumah tangga C (RC) & Rp.5.500 \\
\hline 4 & Niaga Kecil (NK) & Rp.8.800 \\
\hline 5 & Niaga Besar (NB) & Rp.9.400 \\
\hline
\end{tabular}

1. Golongan $\mathrm{RA}=($ Volume air $\mathrm{X} 3.700)+20.000$ (Biaya administrasi)

2. Golongan $\mathrm{RB}=($ volume air $\mathrm{X} 4.100)+20.000$ (Biaya administrasi)

3. Golongan $\mathrm{RC}=($ volume air X 5.500) +20.000 (Biaya administrasi)

4. Golongan $\mathrm{NK}=($ volume air X 8.800 $)+20.000$ (Biaya administrasi)

5. Golongan $\mathrm{NB}=($ volume air $\mathrm{X} 9.400)+20.000$ (Biaya administrasi

Tabel 2. Pengujian perhitungan harga

\begin{tabular}{|l|l|l|l|l|}
\hline $\begin{array}{c}\text { Volum } \\
\text { e air } \\
\text { L }\end{array}$ & $\begin{array}{c}\text { No } \\
\text { Pelangg } \\
\text { an }\end{array}$ & Gol & Harga Total & $\begin{array}{c}\text { Harga } \\
\text { semestinya }\end{array}$ \\
\hline $1.21 \mathrm{~L}$ & 131011 & RB & Rp.24.961 & Rp.24.961 \\
\hline $0.96 \mathrm{~L}$ & 131012 & NK & Rp.28.448 & Rp.28.448 \\
\hline $1.37 \mathrm{~L}$ & 131013 & RC & Rp.27.535 & Rp.27.535 \\
\hline $0.98 \mathrm{~L}$ & 131014 & NB & Rp.29.212 & Rp.29.212 \\
\hline $0.97 \mathrm{~L}$ & 131015 & RA & Rp.23.589 & Rp.23.589 \\
\hline $1.27 \mathrm{~L}$ & 131016 & RB & Rp.25.207 & Rp.25.207 \\
\hline $1.18 \mathrm{~L}$ & 131017 & NK & Rp.30.384 & Rp.30.384 \\
\hline $0.97 \mathrm{~L}$ & 131018 & RB & Rp.23.977 & Rp.23.977 \\
\hline $1.26 \mathrm{~L}$ & 131019 & RC & Rp.26.930 & Rp.26.930 \\
\hline $1.20 \mathrm{~L}$ & 131020 & NK & Rp.30.560 & Rp.30.560 \\
\hline
\end{tabular}

\subsection{Pengujian Telegram Bot}

pengujian sistem telegram bot, dilakukan dengan metode chatting dengan BOT yang diberi nama "water", berdasarkan pengujian tersebut, pelanggan dapat mengecek keberadaan air, dengan mengirimkan pesan "cek air " ke BOT telegram, maka BOT akan mengirimkan pesan balasan berdasarkan kondisi air pada alat.

Pada pengujian telegram BOT, BOT dapat mengirim balasan kondisi air pada alat kepada pelanggan. dengan chat balasan berupa text "Ada air di tabung deteksi" jika terdeteksi air dan "Tidak ada air di tabung deteksi” jika tidak terdeteksi air.

Tabel 3. pengujian pengiriman chat Telegram Bot

\begin{tabular}{|c|c|c|c|c|}
\hline $\begin{array}{c}\text { perco } \\
\text { baan }\end{array}$ & $\begin{array}{c}\text { Wakt } \\
\text { uengi } \\
\text { riman }\end{array}$ & $\begin{array}{c}\text { Wakt } \\
\text { u } \\
\text { Balas } \\
\text { an }\end{array}$ & $\begin{array}{c}\text { Selisih } \\
\text { waktu }\end{array}$ & keterangan \\
\hline I & 21.29 & 21.29 & $\begin{array}{c}06.53 \\
\text { detik }\end{array}$ & $\begin{array}{c}\text { "Tidak ada air di } \\
\text { tabung deteksi" }\end{array}$ \\
\hline II & 21.33 & 21.33 & $\begin{array}{c}07.62 \\
\text { detik }\end{array}$ & $\begin{array}{c}\text { "Tidak ada air di } \\
\text { tabung deteksi" }\end{array}$ \\
\hline III & 21.34 & 21.34 & $\begin{array}{c}03.75 \\
\text { detik }\end{array}$ & $\begin{array}{c}\text { "Ada air di } \\
\text { tabung deteksi" }\end{array}$ \\
\hline IV & 21.56 & 21.56 & $\begin{array}{c}07.88 \\
\text { detik }\end{array}$ & $\begin{array}{c}\text { "Ada air di } \\
\text { tabung deteksi" }\end{array}$ \\
\hline V V & 21.58 & 21.58 & $\begin{array}{c}09.30 \\
\text { detik }\end{array}$ & $\begin{array}{c}\text { "Ada air di } \\
\text { tabung deteksi" }\end{array}$ \\
\hline VI & 10.28 & 10.28 & $\begin{array}{c}10.87 \\
\text { detik }\end{array}$ & $\begin{array}{c}\text { "Ada air di } \\
\text { tabung deteksi" }\end{array}$ \\
\hline VII & 10.31 & 10.31 & $\begin{array}{l}16.55 \\
\text { detik }\end{array}$ & $\begin{array}{c}\text { "Tidak ada air di } \\
\text { tabung deteksi" }\end{array}$ \\
\hline VIII & 10.34 & 10.34 & $\begin{array}{l}11.66 \\
\text { detik }\end{array}$ & $\begin{array}{c}\text { "Tidak ada air di } \\
\text { tabung deteksi" }\end{array}$ \\
\hline IX & 10.36 & 10.36 & $\begin{array}{l}10.81 \\
\text { detik }\end{array}$ & $\begin{array}{c}\text { "Tidak ada air di } \\
\text { tabung deteksi" }\end{array}$ \\
\hline X & 10.37 & 10.37 & $\begin{array}{l}09.26 \\
\text { detik }\end{array}$ & $\begin{array}{c}\text { "Ada air di } \\
\text { tabung deteksi }\end{array}$ \\
\hline
\end{tabular}

Pada pengujian pada table 3 dilakukan pengujian pengiriman chat telegram bot, yang dilakukan sebanyak 10 kali, dengan waktu selisih pengiriman dan penerimaan terbesar adalah 16.55 detik dengan yang terkecil sebesar 03.75.

\subsection{Pengujian Hardware}

Pengujian komponen dari optimasi meteran air ini terdiri dari pengegujian sensor water flow, dan pengujian sensor water Level. Sensor water flow dilakukan pengujian kalibrasi perhitungan volume air, dan sensor water level dilakukan pengujian untuk mendeteksi ada atau tidaknya air, berdasarkan resistansi ohm dari sensor water level.

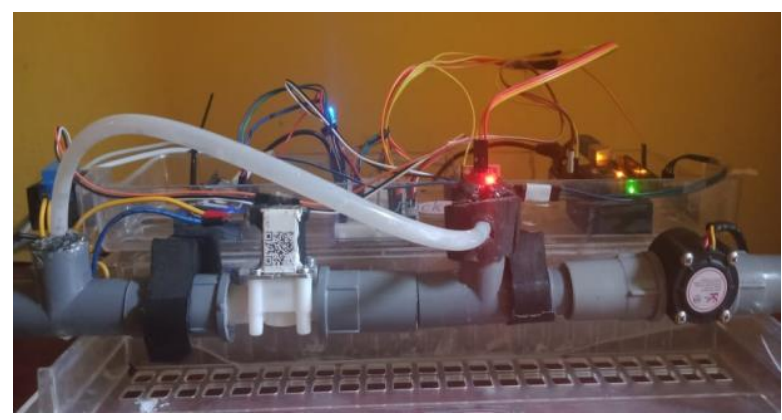

Gambar 13 Implementasi optimasi alternative meteran air

\subsection{Pengujian Sensor water flow}

Pengujian menggunakan sensor water flow YFS201, berfungsi untuk mengukur volume air yang terhitung oleh sensor water flow, dengan mengasumsi 
1 Liter air dan dilakukan percobaan sebanyak 10 kali. Hasil dari perhitungan dari sensor water flow akan disimpan pada database. Hasil pengujian sensor water flow ditunjukan pada tabel 4.

Tabel 4. pengujian kalibrasi sensor water flow

\begin{tabular}{|c|c|c|c|}
\hline Percobaan & ML & $\begin{array}{c}\text { Konversi } \\
\text { ML }\end{array}$ & Konversi L \\
\hline 1 & $1000 \mathrm{ML}$ & $1059 \mathrm{ML}$ & $1.06 \mathrm{~L}$ \\
\hline 2 & $1000 \mathrm{ML}$ & $1188 \mathrm{ML}$ & $1.19 \mathrm{~L}$ \\
\hline 3 & $1000 \mathrm{ML}$ & $1124 \mathrm{ML}$ & $1.12 \mathrm{~L}$ \\
\hline 4 & $1000 \mathrm{ML}$ & $1109 \mathrm{ML}$ & $1.11 \mathrm{~L}$ \\
\hline 5 & $1000 \mathrm{ML}$ & $1052 \mathrm{ML}$ & $1.05 \mathrm{~L}$ \\
\hline 6 & $1000 \mathrm{ML}$ & $1144 \mathrm{ML}$ & $1.14 \mathrm{~L}$ \\
\hline 7 & $1000 \mathrm{ML}$ & $1002 \mathrm{ML}$ & $1 \mathrm{~L}$ \\
\hline 8 & $1000 \mathrm{ML}$ & $1252 \mathrm{ML}$ & $1.25 \mathrm{~L}$ \\
\hline 9 & $1000 \mathrm{ML}$ & $1157 \mathrm{ML}$ & $1.16 \mathrm{~L}$ \\
\hline 10 & $1000 \mathrm{ML}$ & $1120 \mathrm{ML}$ & $1.12 \mathrm{~L}$ \\
\hline Rata-rata & 1000 & 1120.7 & \\
\hline Jumlah & 10000 & 11207 & \\
\hline
\end{tabular}

Berdasarkan data pada Table 4 maka diperoleh hasil analisis pengukuran volume air seperti berikut :

1. Simpangan

$$
\begin{aligned}
& \text { Simpangan }=1000-1120.7 \\
& \text { Simpangan }=120.7
\end{aligned}
$$

Jadi, nilai sim`pangan dari pengukuran volume debit air sensor YF-S201 sebesar 120.7.

2. Presentase error

Presentase error $=\frac{120.7}{1000} \times 100 \%$

Presentase error $=0.1207 \%$

Jadi, presentase error dari pengukuran volume air sensor YF-S201 sebesar $0.1207 \%$

3. Standar Deviasi (SD)

\section{Standar deviasi $=71.79$}

Jadi, nilai standar deviasi dari pengukuran $1000 \mathrm{ml}$ sensor YF-S201 sebesar 71.79.

\begin{tabular}{|c|c|c|c|c|c|}
\hline $\begin{array}{l}\text { Volume } \\
\text { air }\end{array}$ & Debit/menit & $\begin{array}{c}\text { Jumlah } \\
\text { total } \\
\text { volume } \\
\text { air }\end{array}$ & $\begin{array}{c}\text { Volume } \\
\text { konversi } \\
\text { sensor }\end{array}$ & $\begin{array}{l}\text { Waktu } \\
\text { (detik) }\end{array}$ & Selisih \\
\hline $1 \mathrm{Ltr}$ & $2 \mathrm{~L} / \mathrm{mnt}$ & $11 \mathrm{tr}$ & $0.92 \mathrm{Ltr}$ & 21.20 & 0.08 \\
\hline $1 \mathrm{Ltr}$ & $4 \mathrm{~L} / \mathrm{mnt}$ & 2 ltr & $2.09 \mathrm{Ltr}$ & 17.09 & -0.09 \\
\hline $1 \mathrm{Ltr}$ & $2 \mathrm{~L} / \mathrm{mnt}$ & $31 \operatorname{tr}$ & $3.03 \mathrm{Ltr}$ & 22.03 & -0.03 \\
\hline $1 \mathrm{Ltr}$ & $2 \mathrm{~L} / \mathrm{mnt}$ & 4 ltr & $3.98 \mathrm{Ltr}$ & 20.67 & 0.02 \\
\hline $1 \mathrm{Ltr}$ & $3 \mathrm{~L} / \mathrm{mnt}$ & 5 ltr & $5.01 \mathrm{Ltr}$ & 19.22 & -0.01 \\
\hline $1 \mathrm{Ltr}$ & $3 \mathrm{~L} / \mathrm{mnt}$ & $61 \mathrm{tr}$ & $6.11 \mathrm{Ltr}$ & 18.20 & -0.11 \\
\hline $1 \mathrm{Ltr}$ & $3 \mathrm{~L} / \mathrm{mnt}$ & 7 ltr & 7.07 Ltr & 18.58 & -0.07 \\
\hline $1 \mathrm{Ltr}$ & $2 \mathrm{~L} / \mathrm{mnt}$ & $81 \mathrm{tr}$ & $8.02 \mathrm{Ltr}$ & 21.93 & -0.02 \\
\hline $1 \mathrm{Ltr}$ & $3 \mathrm{~L} / \mathrm{mnt}$ & $91 \mathrm{tr}$ & $9.09 \mathrm{Ltr}$ & 18.02 & $\begin{array}{l}-0.09 \\
\end{array}$ \\
\hline $1 \mathrm{Ltr}$ & $2 \mathrm{~L} / \mathrm{mnt}$ & $10 \mathrm{ltr}$ & $9.96 \mathrm{Ltr}$ & 22.08 & 0.04 \\
\hline \multicolumn{5}{|l|}{ RAT } & -0.028 \\
\hline
\end{tabular}

Tabel 5. Pengujian volume air sensor YF-S201

Pengujian menggunakan sensor water flow $Y F$ S201, berfungsi untuk mengukur volume air yang terhitung oleh sensor water flow, dengan mengasumsi 1 Liter air dan dilakukan percobaan sebanyak 10 kali. Pada hasil uji coba penghitungan volume air diperoleh rata-rata selisih konversi sensor sebesar -0.028 .

\subsection{Pengujian sensor water level}

Pada pengujian sensor water level dilakukan uji coba dalam menentukan nilai resistansi sensor untuk sebagai pengontrol buka tutupnya katup solenoid valve. Dengan menghubungkan pin signal sensor water level ke pin analog (A0), sedangkan pin VCC dihubungkan ke pin $\mathrm{VCC}(5 \mathrm{~V})$ arduino, kemudian pin GND sensor water level dihubungkan ke pin GND Arduino.Pengujian dilakukan dengan 3 kondisi yang sesuai dengan penelitian ini yaitu, percikan air, air mengalir, air tidak mengalir.

\begin{tabular}{|c|c|c|c|}
\hline No & Percikan air & Air mengalir & $\begin{array}{l}\text { Setelah air } \\
\text { mengalir }\end{array}$ \\
\hline 1 & 384 & 633 & 427 \\
\hline 2 & 384 & 636 & 570 \\
\hline 3 & 369 & 564 & 363 \\
\hline 4 & 409 & 564 & 500 \\
\hline 5 & 367 & 430 & 313 \\
\hline 6 & 392 & 423 & 494 \\
\hline 7 & 363 & 512 & 303 \\
\hline 8 & 393 & 473 & 384 \\
\hline 9 & 385 & 531 & 320 \\
\hline 10 & 359 & 378 & 374 \\
\hline 11 & 384 & 534 & 329 \\
\hline 12 & 359 & 384 & 353 \\
\hline 13 & 380 & 541 & 321 \\
\hline 14 & 363 & 391 & 355 \\
\hline 15 & 385 & 514 & 317 \\
\hline 16 & 363 & 396 & 359 \\
\hline 17 & 385 & 460 & 320 \\
\hline 18 & 363 & 430 & 361 \\
\hline 19 & 388 & 474 & 313 \\
\hline 20 & 366 & 437 & 354 \\
\hline 21 & 395 & 443 & 317 \\
\hline 22 & 366 & 436 & 354 \\
\hline $\begin{array}{c}\text { Rata- } \\
\text { rata }\end{array}$ & 377.3 & 481.09 & 368.2 \\
\hline Jumlah & 8302 & 10584 & 8101 \\
\hline MAX & 409 & 636 & 570 \\
\hline MIN & 359 & 378 & 303 \\
\hline
\end{tabular}

Tabel 6. Pengujian sensor water level

Berdasarkan data pada Table 6. maka diperoleh hasil analisis pengujian sensor water level untuk mendeteksi keberadaan air seperti berikut :

1. Nilai resistansi maximal water level saat percikan air adalah 409 dan terkecil 359.

2. Nilai resistansi maximal water level saat air mengalir adalah 636 dan terkecil 378.

3. Nilai resistansi maximal water level setelah air mengalir adalah 570 dan terkecil 303.

\section{6. pengujian solenoid valve}

Pada pengujian solenoid valvel dilakukan dengan menentukan standar nilai water level, sebagai nilai penunjuk untuk membuka dan menutup kran solenoid valve. 
Tabel 7. Tabel pengujian solenoid valve

\begin{tabular}{|l|l|l|}
\hline No & \multicolumn{1}{|c|}{$\begin{array}{c}\text { Selisih waktu } \\
\text { terbuka }\end{array}$} & \multicolumn{1}{|c|}{$\begin{array}{c}\text { Selisih detik } \\
\text { menutup solenoid }\end{array}$} \\
\hline 1 & 03.34 detik & 31.90 detik \\
\hline 2 & 41.40 detik & 45.40 detik \\
\hline 3 & 1.10 .40 Menit & 22.16 detik \\
\hline 4 & 47.10 detik & 50.26 detik \\
\hline 5 & 13.72 detik & 51.57 detik \\
\hline 6 & 17.93 detik & 44.82 detik \\
\hline 7 & 02.02 .10 menit & 57.79 detik \\
\hline 8 & 15.40 detik & 49.65 detik \\
\hline 9 & 02.40 .00 menit & 01.02 .00 menit \\
\hline 10 & 08.86 detik & 49.18 detik \\
\hline
\end{tabular}

Pada pengujian table 7 dilakukan uji coba dalam tingkatan respond solenoid dalam membuka dan menutup katup. Dari hasil uji coba yang dilakukan sebanyak 10 kali diperoleh bahwa selisih waktu terbesar saat selonoid valve membuka katup adalah 02.40.00 menit dan yang terkecil 03.34 detik. Sedangkan waktu terbesar saat solenoid valve menutup katup sebesar 01.02.00 menit dan yang terkecil sebesar 22.16 detik. Ini dikarenakan pembacaan nilai resistansi sensor water level yang masih menunjukan kelembapan.

\section{7. pengujian lampu indicator Led RGB}

Pengujian lampu Led RGB sebagai indikator penunjuk total volume pemakaian air. Lampu led Biru akan menyala selama total volume pemakaian air lebih kecil dari 10 Liter.

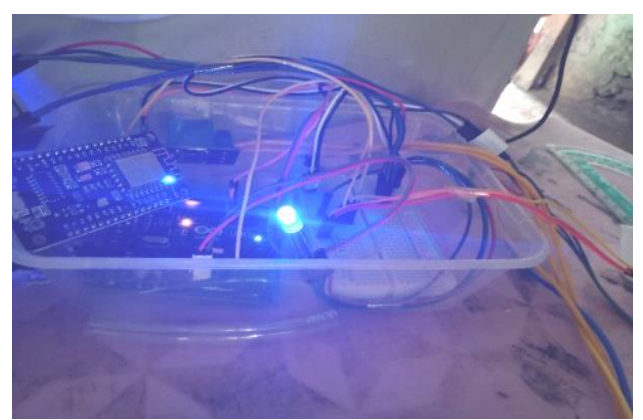

Gambar 14 pengujian lampu Led Biru

Lampu led Hijau akan menyala selama total volume air lebih besar sama dengan 10 Liter dan lebih kecil sama dengan 20 Liter $(>=10$ ltr $\& \&>=201$ tr).

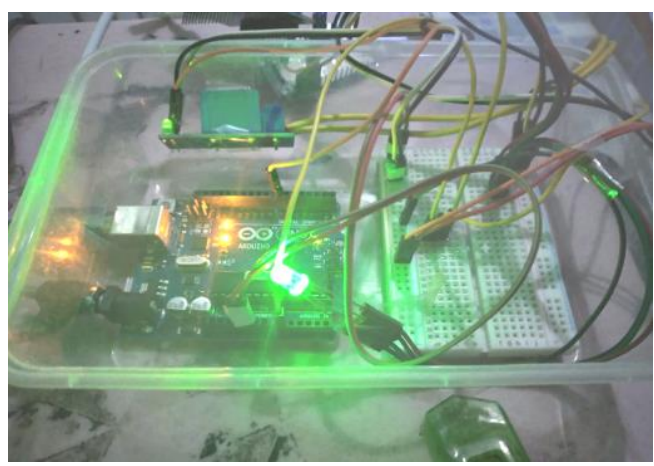

Gambar 15 pengujian lampu led Hijau
Lampu led merah akan menyala selama total volume pemakaian air lebih besar dari 20 Liter (> $20 \mathrm{ltr})$.

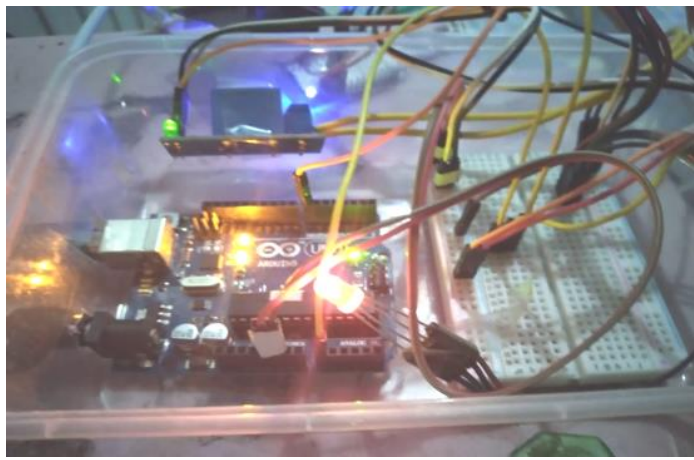

Gambar 16 pengujian lampu led merah

\section{KESIMPULAN DAN SARAN}

\subsection{Kesimpulan}

Berdasarkan beberapa pengujian yang telah dilakukan didapatkan kesimpulan :

1. Dari hasil pengujian perangkat lunak menunjukkan hasil bahwa semua fitur program "optimasi meteran air berbasis IOT" dapat berjalan sesuai dengan fungsinya.

2. Dari hasil pengujian pengiriman chat bot "telegram" menunjukan pengriman balasan chat bot sesuai dengan kondisi air pada sistem.

3. Dari hasil pengujian Solenoid valve masih menunjukan selisih dimana selisih terbesar saat selonoid valve membuka katup adalah 02.40 .00 menit, dan saat menutup katup sebesar 01.02.00 menit.

4. Dari hasil pengujian sensor water flow menunjukan presentase error sebesar $0.1207 \%$ dan nilai standar deviasi dari pengukuran $1000 \mathrm{ml}$ sensor YF-S201 sebesar 71.79.

5. Dari hasil pengujian perhitungan tagihan pemakaian menunjukan perhitungannya sesuai dengan perhitungan harga golongan PDAM Kab.kupang.

\subsection{Saran}

Berdasarkan penelitian yang telah dilakukan, maka penulis dapat memberikan saran-saran untuk pengembangan selanjutnya antar lain :

1. Pada penelitian selanjutnya dapat mengganti sensor water level dengan sensor water yang lain seperti sensor raindrop atau Soil Moisture sensor, agar pembacaan nilai resistansi saat air tidak menggalir lebih akurat..

2. Menambahkan baterai atau panel surya sebagai alternatif daya listrik saat pasokan daya listrik tidak ada.

3. Menambahkan fitur pembayaran otomatis pada sistem. Agar mempermudah pelanggan dalam pembayaran tagihan.

4. Menambah fitur notifikasi pengingat pada jadwal bayar Tagihan PDAM. 


\section{DAFTAR PUSTAKA}

[1] Wahyu indianto, Awang Harsa Kridalaksana, Yulianto. 2017. Perancangan sistem prototipe pendeteksi banjir peringatan dini menggunakan arduino dan php. Jurnal Informatika Mulawarman, Samarinda.

[2] Puthut Kurniawan1, Rozeff Pramana, S.T., M.T, Deny Nusyrwan, S.T., M.Sc. 2017. Prototype sistem deteksi kebocoran air dan pengurasan secara otomatis pada kapal berbasis arduino uno dan labview. Teknik Elektro. Universitas Maritim Raja Ali Haji.

[3] Sutono. 2016. Monitoring Distribusi Air Bersih. Jurnal Ilmiah SETRUM, Universitas Komputer Indonesia.

[4] I Made Nova Suardiana, I Gusti Agung Putu Raka Agung, Pratolo Rahardjo. 2017. Rancang Bangun Sistem Pembacaan Jumlah Konsumsi Air Pelanggan PDAM Berbasis Mikrokontroler ATMEGA328Dilengkapi SMS. Teknologi Elektro.

[5] Nelly Indriani Widiastuti, Rani Susanto. Kajian sistem monitoring dokumen akreditasi teknik informatika unikom. Majalah Ilmiah UNIKOM, Vol.12 No. 2. Fakultas Teknik dan Ilmu Komputer Universitas Komputer Indonesia.
[6] Roky Triadi, Dedi Triyanto, Ilhamsyah. Prototype sistem keran air otomatis berbasis sensor flowmeter pada gedung bertingkat. Jurnal coding sistem komputer Untan, Vol.03 No.3. Jurusan Sistem Komputer, Fakultas MIPA Universitas Tanjungpura.

[7] https://lastminuteengineers.com/water-levelsensor-arduino-tutorial/.Diakses pada tanggal 11 februari 2021.

[8] Nurul Hidayati Lusita Dewi, Mimin F. Rohmah, Soffa Zahara.2018. PROTOTYPE SMART HOME DENGAN MODUL NODEMCU ESP8266 BERBASIS INTERNET OF THINGS (IOT). Mahasiswa Teknik Informatika Universitas Islam Majapahit.

[9] Aulia Wiendyka Yudha, Retnowati, Rahmadwati. 2015. perancangan sistem pengaturan tekanan pada shutdown valve untuk antisipasi kebakaran berbasis pneumatic menggunakan mikrokontroler atmega 328. Teknik Elektro Universitas Brawijaya.

[10] https://www.bukugue.com/apa-itu-bottelegram/. Diakses pada tanggal 3 januari 2021. 